\title{
A MOLECULAR AND SEROLOGICAL SURVEY ON CRIMEAN CONGO HAEMORRHAGIC FEVER IN IRANIAN CHILDREN
}

\author{
S. Chinikar, R. Mirahmadi, M. Moradi, M. Ghiasi, S. Khakifirouz, F. Sadat Varai, M. Asl Solaimani, A. \\ Hasan Zehi \\ Virology, Institute of Medicine Pasteur of Iran, Tehran, Iran
}

Background: Crimean Congo Haemorrhagic Fever (CCHF) is a viral zoonotic disease with mortality rate up to $50 \%$. The virus is from Nairovirus genus, Bunyaviridae family. Humans are infected by tick bite, handling of infected blood or tissues and nosocomially. In this study, children's probable sera for CCHF from all over the country were analyzed by serological and molecular assays.

Methods: Sera of Iranian probable children, under 15 years old, were collected from June 2000 to 13 February 2011 and analyzed by specific Elisa (anti CCHF IgM and IgG detection) and by RT-PCR (gel based and Real time) in the laboratory of Arboviruses and Viral Haemorrhagic Fevers of the Pasteur Institute of Iran (National Reference Lab).

Results: Our serological and molecular findings demonstrated the number of probable, confirmed and death cases are 168, 48 and 3 respectively. Among confirmed cases, 16 were IgM and RT-PCR positive and 14 cases were only RT-PCR positive, $(60.4 \%)$ were boy and $(39.6 \%)$ were girl. The results showed that the most infected province with $68.7 \%$ of confirmed cases was Sistan-va-Baluchestan.

Conclusions: As Sistan-va-Baluchestan is bordering two CCHF endemic countries, Afghanistan and Pakistan, it had the highest rate of infection. The Iranian strain is very similar to the Matin strain of Pakistan. $\mathrm{CCHF}$ in boys is more prevalent than girls, which seems due to boy contribution in high risk professions related to infected livestock. Thus, with a continuous training program for these children, the incidence of $\mathrm{CCHF}$ in the endemic regions will be decreased. 